\title{
Ulusal Jinekoloji ve Obstetrik Kongresi'nde Üreme Endokrinolojisi ve İnfertilite Alanında Sunulan Bildirilerin Uluslararası Yayına Dönüştürülme Oranları
}

The International Publication Rates of Abstracts Presented in The National Gynecology and Obstetrics Meetings in The Field of Reproductive Endocrinology and Infertility

\author{
Gülçin Şahin Ersoy ${ }^{1}$, Meryem Eken ${ }^{2}$, Deniz Öztekin ${ }^{3}$ \\ Ebru Çöğendez ${ }^{2}$, Mustafa Eroğlu ${ }^{2}$
}

1. Dr. Lütfi Kırdar Kartal Eğitim ve Araştırma Hastanesi Kadın Hastalıkları ve Doğum Kliniği, Istanbul

2. Zeynep Kamil Kadın ve Çocuk Hastalıkları Eğitim ve Araştırma Hastanesi Kadın Hast. ve Doğum Kliniği, İstanbul

3. Tepecik Eğitim ve Araştırma Hastanesi Kadın Hastalıkları ve Doğum Kliniği, İzmir

$\ddot{O Z Z T}$

Amaç: Üreme endokrinolojisi ve infertilite, tüm dünyada kadın hastalıkları ve doğum disiplini içerisinde bilimsel ilerlemenin en hizlı olduğu alanlardandır. Ulusal kongrelerde bu alanda sunulmuş bildirilerin analiz edildiği bir araştırma henüz yapılmamıştır. Bu nedenle Ulusal Jinekoloji ve Obstetrik Kongresi'nde 2008-2010 yulları arasinda sunulmuş bildiriler incelenerek Türk araştırmacıların üreme endokrinolojisi ve infertilite alanında dünya literatürüne katkılarının belirlenmesi ve gerçekleştirilen kongrenin bu alandaki bilimsel düzeyinin ortaya konulması hedeflenmiştir.

Gereç ve Yöntemler: 2008-2010 yilları arasında Ulusal Jinekoloji ve Obstetrik Kongreleri'nde üreme endokrinolojisi ve infertilite alanında sunulan tüm bildiriler çalışmamıza dahil edilmiştir. Bilimsel araştırmaların uluslararası hakemli dergilerde yayına dönüștürülme durumlarının saptanması için PubMed ve Google Scholar veri tabanlart tarandl. Makale veri tabaninda saptandiktan sonra; yazar isimleri, yayınlandikları dergi isimleri, yayınlanma tarihleri, yazarın çalıştığ kurum bilgileri kaydedildi.

Bulgular: 2008-2010 yillarl arasinda Ulusal Jinekoloji ve Obstetrik Kongresi'nde üreme endokrinolojisi ve infertilite alanında 19'u (\%11,8) sözel, 142 'si $(\% 88,2)$ poster olmak üzere toplam 161 bildiri sunulmuştur. Bunların 46'sı $(\% 28,6)$ Pubmed ve Google Scholar veri tabanina kayttl uluslararasi hakemli dergilerde makale olarak yayınlanmıştır. Sözel bildirilerin uluslararası dergilerde yayılanma oranı \%68,4 (13), posterlerin $\% 23,2$ (33) bulunmuştur. [Odds oranı $=7,14, \% 95$ güven aralı̆̆ $(G A): 2,52-20,4 p<0,001]$. Bildirilerin kongrede sunulduktan sonra makale olarak yayinlanmalarina kadar geçen süre ortalama 17,5 $\pm 12,5$ ay olarak tespit edilmiştir. Kurum tipine göre bildirileri incelediğimizde en yüksek yayınlanma oranina üniversite hastaneleri sahipken $(\% 33,3)$ üniversite hastaneleri ve diğer kurumlar arasında istatistiksel olarak anlamlı bir fark saptanmamıştır $(p=0,113)$.

Sonuç: 2008-2010 Ulusal Jinekoloji ve Obstetrik Kongre'lerinde üreme endokrinolojisi ve infertilite alaninda sunulan bildirilerin yayınlanma oranı ülkemizdeki diğer branşlarda yapilan kongre bildilerine klyasla yüksek orandadır. Yine de bu oranın arttırllip yabancı bildirilerle ayn düzeye gelmesi ve Türkiye'de gerçekleştirilen çalışmaların daha geniş çevrelere duyurulabilmesi için araştırmacıları yayına teşvik edici yöntemlerin geliştirilmesi, yayına dönüştürülme oranlarında karşılaşılan düşüklüğün olası sebeplerinin irdelenmesi ve çözülmesi gerektiğine inanmaktayı.

Anahtar Kelimeler: kongre, makale, toplantı özeti

İletişim Bilgileri:

Yazışmadan Sorumlu Yazar: Gülçin Şahin Ersoy

Yazışma Adresi: Zümrütevler Mah, Nish Adalar Sitesi,

B:25 D:35 Maltepe, 34852 Istanbul, Türkiye

E-mail: gulcinsahinmd@gmail.com

Makalenin Geliş Tarihi: 12.10.2014

Makalenin Kabul Tarihi: 25.12.2014

\section{ABSTRACT}

Aim: Among the discipline of obstetrics and gynecology, reproductive endocrinology and infertility is worldwide regarded as one of the fields witnessing the fastest scientific developments. However an analysis of relevant presentations held at the national meetings has not been performed yet. The objective of this study therefore was to determine the contribution of Turkish scientists to world literature in the field of reproductive endocrinology and infertility, reflecting the scientific level of the annual National Gynecology and Obstetrics Meetings.

Materials and Methods: All presentations in the field of reproductive endocrinology and infertility held in the National Gynecology and Obstetrics Meetings between 2008 and 2010 were included into the study. The PubMed and Google Scholar databases were searched in order to detect the conversion of scientific studies to publication in international peer-reviewed journals. For all abstracts, parameters including institution, author details, publication time and journal titles were recorded.

Results: Between 2008 and 2010161 abstracts (19 of which were oral presentations; $11.8 \%$ ) were presented in the National Gynecology and Obstetrics Meetings in the field of reproductive endocrinology and infertility. $28.6 \%$ of these abstracts $(n=46)$ were published in international peer-reviewes journals indexed in PubMed or Google Scholar databases. Compared with posters, the publication rate of oral presentations was found to be significantly higher $[23.2 \%$ vs. $68.4 \%$; Odds ratio $=7.14,95 \%$ confidence interval (CI): 2.52 - $20.4 p<0.001]$. The mean time to publication following the congress was $17.5 \pm 12.5$ months. The type of institution had no significant effect on the publication rate, nevertheless the university hospitals had the highest rate $(33.3 \% ; p=0.113)$.

Conclusion: The overall publication rate for the abstracts concerning reproductive endocrinology and infertility presented at the National Gynecology and Obstetrics Meetings held between 2008 and 2010 was found to be higher than the rates of national meetings of other subspecialities in Turkey. In order to further enhance this rate and level it with the publication rates of international meetings new and effective methods should be developed to inspire the researchers. In order to convey Turkey-based studies to a wider range of audience worldwide, the reasons for the relatively low level of publication rate should be effectively sought and dealt with.

Keywords: congress, article, abstracts 


\section{GİRIŞ}

Bilimsel kongreler uzmanlık alanları ortak olan araștırmacıların bilimsel çalıșmalarını diğer meslektaşlarıyla paylaștıkları ve geri bildirim aldıkları geniş katılımlı organizasyonlardır [1]. Gerçekleştirilen bu paylaşım ve karşılıklı etkileşim sunulan çalışmaların daha da geliştirilmesine ve bilgi düzeyinin arttırılmasına ciddi katkılar sağlamaktadır. Çalıșmaların bilimsel toplantılarda sunulması kadar uluslararası alanda yayına dönüştürülerek daha geniş kitlelere ulaştırılması da oldukça önem taşımaktadır [2]. Çalışmanın uluslararası hakemli dergilerde yayına dönüştürülmesi hem sözkonusu araştırmanın genel anlamda kalitesini yansitan hem de kongrenin bilimsel düzeyini ortaya koyan saygın bir ölçüttür [3]. Yapılmış bir Cochrane meta-analizinde, bilimsel kongrelerde sunulan bildirilerin yayına dönüștürülme oranı $\% 44.5$ olarak tespit edilmiștir[4]. Ülkemizde düzenlenen ulusal kongrelere yönelik araștırmalar nispeten daha sınırlı olmakla birlikte çeşitli bildirilerde bu oran \%11.8 ile \%20.4 arasında değişmektedir [5-8].

Üreme endokrinolojisi ve infertilite, tüm dünyada kadın hastalıkları ve doğum disiplini içerisinde bilimsel ilerlemenin en hızlı olduğu alanlardandır. Ulusal kongrelerde bu alanda sunulmuş bildirilerin analiz edildiği bir araştırma henüz yapılmamıştır. Bu nedenle Ulusal Jinekoloji ve Obstetrik Kongresi'nde 2008-2010 y1lları arasında üreme endokrinolojisi ve infertilite alanında sunulmuş bildiriler incelenerek Türk araștırmacıların üreme endokrinolojisi ve infertilite alanında dünya literatürüne katkılar1nın belirlenmesi ve gerçekleştirilen kongrenin bu alandaki bilimsel düzeyinin ortaya konulmas1 hedeflenmiştir.

\section{GEREÇ VE YÖNTEMLER}

2008-2010 y1llar1 arasında düzenlenen Ulusal Jinekoloji ve Obstetrik Kongreleri'nde üreme endokrinolojisi ve infertilite alanında sunulan tüm poster ve sözel bildiriler taranmak üzere çalıșmamıza dahil edilmiștir. Bildirilerle ilişkili verilere kongre resmi web sitesinden ulaşıldı. Bilimsel araştırmaların uluslararası hakemli dergilerde yayına dönüştürülme durumlarının saptanması için Ağustos 2014 itibariyle PubMed (http://www.ncbi.nlm.nih.gov) ve Google Scholar (http://scholar.google.com.tr) veri tabanları tarandı. Verilen süre kongre bildirilerinin yayına dönüștürülmesi için yeterli kabul edildi $[9,10]$. Başlangıç taramada birinci yazar ismi ve yanlarında bildiri başlığından seçilen bir anahtar sözcük kullanıldı. Makale bulunamadığı takdirde birinci yazardan başlayarak son yazar ismine kadar sırasıyla yazar isimleri ve yanlarında bildiri başlığından seçilen bir anahtar sözcük girildi [11]. Bu taramalar sonucunda makale halen bulunamamıșsa her bir yazar ismi tek tek girildi ve tüm makaleleri tarandi. Makalenin bildiriyle eşleşmiş olarak kabul edilebilmesi için, hipotez ve çalışma dizaynının aynı olması ve en az bir ortak yazarın bulunması koşulu arandı. Makale saptandiktan sonra; yazar isimleri, yayınlandıkları dergi isimleri, yayınlanma tarihleri, yazarın çalıştığ kurum bilgileri veri olarak kaydedildi. Eğer yazarlar, farklı kurumlarda görev yapıyorsa ve araștırmanın yapıldığı kurum belirtilmemişse sadece birinci yazarın kurumu çalışmanın yapıldığı kurum olarak kabul edildi. Yayınlanma tarihleri ay ve yıl şeklinde kaydedildi, eğer veri yıl ve takip eden 2 ay içeriyorsa ilk yazılan ay, sadece yılı içeriyorsa Haziran yayınlanma ayı olarak kabul edildi [1]. Bildiriler sunum tipine göre sözel ve poster olarak 2 grupta, çalışma tipine göre ise olgu sunumu, klinik çalışma ve deneysel çalışma olmak üzere üç farklı grupta incelendi.

Verilerin analizinde SPSS (Statistical Package for the Social Sciences) v17 programından faydalanıldı (SPSS Inc., Chicago, IL, Amerika). Istatistiksel analizde numerik veriler için bağımsız örneklem $\mathrm{T}$ testi, kategorik veriler için ki-kare testi kullanıldı. Sayısal değişkenler ortalama ve standart sapma ile kategorik değişkenler yüzde olarak sunuldu. Sonuçlar \%95 güven aralığında değerlendirildi, $p$ değeri $<0.05$ olduğunda anlamlı kabul edildi.

\section{BULGULAR}

2008-2010 yılları arasında Ulusal Jinekoloji ve Obstetrik Kongresi'nde üreme endokrinolojisi ve infertilite alanında 19 'u $(\% 11,8)$ sözel, 142'si $(\% 88,2)$ poster olmak üzere toplam 161 bildiri sunulmuştur. Bunların 46'sı $(\% 28,6)$ Pubmed ve Google Scholar veri tabanına kayıtl1 uluslararası hakemli dergilerde makale olarak yayınlanmıștır. Yayına dönüştürülen bildirileri sunum tipine göre incelediğimizde sözel bildirilerin uluslararası dergilerde yayınlanma oran1 \%68,4 (13), poster bildirilerin \%23,2 (33) bulunmuştur. Buna göre yayınlanma oranları arasındaki fark istatistiksel olarak anlamlıdır [Odds oran $1=7,14 \% 95$ güven aralığ 1 (GA): $2,52-20,4 p<0,001]$. Üreme endokrinolojisi ve infertilite alanında en fazla sayıda bildiri $(\mathrm{n}=$ 62), 2010 y1lı 8. Ulusal Jinekoloji ve Obstetrik Kongresi'nde sunulmuştur. Yine 2010 yılında makaleye dönüștürülen bildirilerin oran1 \%40,3 olarak diğer yıllardaki kongrelerden daha yüksek saptanmıştır $(\mathrm{p}=0,03)$ (Tablo 1). Bildirilerin ulusal kongrede sunulduktan sonra makale olarak yayınlanmalarına kadar geçen süre orta- 
Tablo 1. Bildirilerin kongre yıllarına, araştırma tipine, kurumlara göre yayına dönüştürülme oranları.

\begin{tabular}{|c|c|c|c|}
\hline & Yayın (+) n(\%) & Toplam n(\%) & $\mathrm{P}$ \\
\hline \multicolumn{4}{|l|}{ Kongre Yılı } \\
\hline 2008 & $10(\% 21,2)$ & $47(\% 100)$ & \multirow{3}{*}{0,033} \\
\hline 2009 & $11(\% 21,1)$ & $52(\% 100)$ & \\
\hline 2010 & $25(\% 40,3)$ & $62(\% 100)$ & \\
\hline \multicolumn{4}{|l|}{ Araştırma Tipi } \\
\hline Olgu Sunumu & $4(\% 10,2)$ & $39(\% 100)$ & \multirow{3}{*}{$<0,001$} \\
\hline Klinik Araştırma & $31(\% 29,2)$ & $106(\% 100)$ & \\
\hline Deneysel Araştırma & $11(\% 68,7)$ & $16(\% 100)$ & \\
\hline \multicolumn{4}{|l|}{ Kurum Tipi } \\
\hline Üniversite & $32(\% 33)$ & $96(\% 100)$ & \multirow{4}{*}{$0,56^{*}$} \\
\hline $\mathrm{EAH}^{\mathrm{a}}$ & $14(\% 28.5)$ & $49(\% 100)$ & \\
\hline $\mathrm{DH}^{\mathrm{b}}$ & $0(\% 0)$ & $2(\% 100)$ & \\
\hline Özel Kurumlar & $0(\% 0)$ & $14(\% 8.7)$ & \\
\hline
\end{tabular}

a Eğitim ve Araştırma Hastanesi, ${ }^{\mathrm{b}}$ Devlet Hastanesi,

* Üniversite hastaneleri ile eğitim ve araştırma hastaneleri arasındaki fark.

lama 17,5 $\pm 12,5$ ay olarak tespit edilmiştir. $\mathrm{Bu}$ süre sözel bildiriler için $20,9 \pm 11.1$ ay, poster bildiriler için $16,2 \pm 12,7$ aydır $(p=0,261)$. Bildirilerin büyük kısmı $(\% 89,9)$ kongre sonrası ilk 3 yıl içerisinde uluslararası dergilerde yayınlanmak üzere makaleye dönüștürülmüștür. 5 bildiri ise $(\% 10,1)$ kongre tarihinden önce makaleye dönüştürülmüş çalışmalardır.

Kurum tipine göre bildirileri incelediğimizde en yüksek yayınlanma oranına üniversite hastaneleri sahipken $(\% 33,3)$ üniversite hastaneleri ve diğer kurumlar arasında istatistiksel olarak anlamlı bir fark saptanmamıştır $(\mathrm{p}=$ 0,113) (Tablo 1). Bununla birlikte devlet hastanelerinden ve özel kurumlardan gönderilen bildirilerin hiç biri uluslararası yayına dönüştürülmemiștir. Araştırma tipine göre bakıldığında en yüksek yayına dönüştürülme oranına $(\% 68,7)$ deneysel çalışmalar sahiptir $(\mathrm{p}<0,001)$. Bunu klinik çalışmalar ardından da olgu sunumları izlemektedir. Olgu sunumlarının yayınlanma oranı klinik araştırmalardan daha düşük olsa da aradaki fark istatistiksel olarak anlamlı çıkmamıştır (Tablo 1). Toplam 21 farklı uluslararası hakemli dergide makaleye dönüştürülen bildirilerin $\% 41,3$ 'ü üç dergide yayınlanmıştır (Şekil 1). Yazar isim değișiklikleri incelendiğinde s1ralamaya bakılmaksızın makalelerin \%63'ünde yazar değișikliği yapıldığı saptanmıștır. Sözel bildirilerde yapılan yazar değişikliği oranı $\%$ 69,2 iken poster bildirilerde $\% 60,6$ dir. Bildiri tipine göre yazar değişikliği oranlarında istatistiksel olarak fark saptanmamıștır. Yapılan yazar isim değişiklikleri, yeni isim ekleme (\%23.9), isim çıkarma (\%19.6) ve hem ekleme hem de çıkarma (\%19.6) şeklinde olmuştur.

\section{TARTIŞMA}

Çalışmamızda 2008-2010 yılları arasında üreme endokrinolojisi ve infertilite alanında sunulan sözel ve poster bildirilerin analizinde toplam uluslararası yayına dönüştürülme oran1 \%28,6 olarak saptand1. Bu oran her ne kadar ülkemizde kongre bildirilerinin uluslararas1 düzeyde yayına dönüștürülmesi ile ilgili yapılmış çalışma sayısı yetersiz olsa da dermatoloji, radyoloji gibi birkaç uzmanlık alanına ait ulusal kongrelerin incelendiği çalışmalarda saptanan oranlardan daha yüksektir (Tablo 2). Buna karşın yurtdışında gerçekleştirilen kongrelerde sunulan bildirileri inceleyen çalışmalarda sunumların uluslararası hakemli dergilerde yayına dönüştürülme oranları daha yüksek bulunmuştur [1, 12-14]. Ülkemizde bu oranın düşük olmasının yabancı dil, zaman ve bilgi yetersizliğine bağlı olabileceğini düşünmekteyiz. Bununla birlikte pozitif sonuç elde edilemeyen çalışmalarda araştırmacının çalışmaya olan güveninin kaybı, araştırma sonuçlarının bilime yeni bir katkıda bulunamaması ve araştırmacıyı yayına teşvik edecek faktörlerin yetersizliği de Türk araștırmacılar tarafindan gerçekleștirilen çalışmaların uluslararası hakemli dergilerde yayına dönüşme oranının düşük olmasına yol açan diğer olası nedenler içerisinde sayılabilir. Diğer taraftan yayınlanma oranlarını yıl bazında değerlendirdiğimizde 2010 yll Ulusal Jinekoloji ve Obstetrik Kongresi'nde sunulan üreme endokrinolojisi ve infertilite alanındaki bildirilerin 2008 ve 2009 yllarındaki kongre bildirilerine göre istatistiksel olarak anlamlı düzeyde daha yüksek olması $(\% 40,3)$, zaman içerisinde ülkemizde üreme endokrinolojisi ve infertilite alanında daha iyi çalışmaların yapılmaya başlandığını desteklemektedir.

Çoğunlukla daha iyi tasarım ve metodolojiye sahip, bilimsel değeri daha yüksek olan bildiri başvuruları kongre bildiri değerlendirme komisyonu tarafindan sözel sunum olarak kabul edilmektedir. Bundan dolayı bildirilerin türüne göre bakıldığında sözel sunumların poster sunumlara kiyasla istatistiksel olarak anlamlı düzeyde yüksek yayına dönüștürülme oranına sahip olması beklendik bir sonuçtur. Literatürde bu durumu destekleyen çalışmalar olmakla birlikte [18-21], bildiri tipinin yayına dönüştürülme oranını etkilemediği kongreler de vardır [22-25]. Bildirilerin ortalama yayına dönüşme süresi literatürdeki diğer çalışmalarla benzer olarak $17,5 \pm 12,5$ ay tespit edildi [5-7, 15-17] 


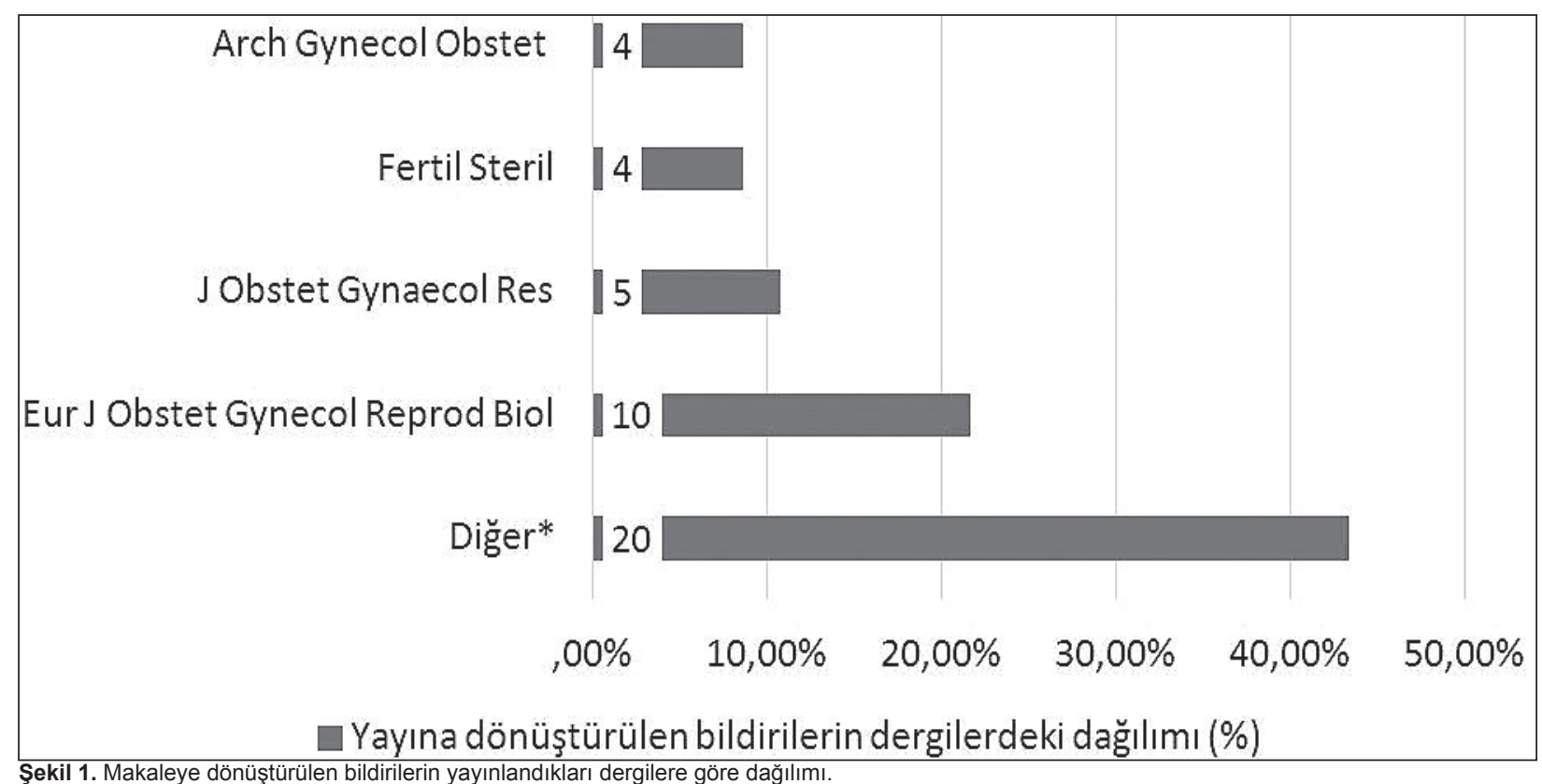

Yayına dönüștürülen bu bildirilerin \% 89,9'unun ilk 3 yıl içerisinde makale olarak yayınlandığı saptandi. Bu durum bildirilerin çoğunun kongreyi takip eden ilk dört y1l içinde yayına dönüştürüldüğünü savunan diğer araştırma bulgularını desteklemektedir [4, 26-30]. Türkiye'de gerçekleştirilmiş olan ulusal kongreleri inceleyen araştırmaların bazılarında çok daha düşük yayınlanma oranlarının saptanmış olması bu durumun dikkate alınmamış olmasından kaynaklanabilir [5, 7]. Biz çalıșmamızın gerçek bir yayınlanma oranını yansıtabilmesi için bu tespite uygun minimum dört yıllık bir zaman aralığı belirledik ve bu aralığa uyan yıllardaki kongre bildirilerini analiz ettik. Diğer taraftan bu dört yıllık sürenin de bir çalışmanın yayına dönüștürülmesi için uzun olduğunu düşünmekteyiz. Zira yayınlanan makaledeki veriler dört yıl öncesine ait olmuş olup bu sürede güncelliğini yitirebilir ve bilime katkıs1 geride kalır. Bu sürenin uzun olmasının nedeninin hem yazar hem de dergi kaynaklı olduğunu düşünüyoruz. Yazarların aynı zamanda klinik alanda da çalışıyor olmaları makale yazımı için gereken boş zamanın kısalmasına böylece yazım sürecinin uzamasina neden oluyor, bununla birlikte dergilerin değerlendirme süreçlerinin uzun

Tablo 2. Çeşitli ulusal kongrelerin bildiri analizleri.

\begin{tabular}{|c|c|c|c|c|c|}
\hline Kongreler & $\begin{array}{c}\text { Analiz Edilen } \\
\text { Yıllar }\end{array}$ & $\begin{array}{c}\text { Çalışmanın } \\
\text { Yılı }\end{array}$ & $\begin{array}{c}\text { Yayına } \\
\text { Dönüştürülme } \\
\text { Oranı }(\%)\end{array}$ & $\begin{array}{c}\text { Yayına } \\
\text { Dönüş̧türülme } \\
\text { Süresi (\%) }\end{array}$ & İncelen Bildiri Tipi \\
\hline Fizyoterapide Gelişmeler Sempozyumu [8] & 2002-2008 & 2013 & 20,4 & $20,9 \pm 16,6 a$ & Sözel \\
\hline Ulusal Romatoloji Kongresi [5] & 2005-2009 & 2011 & 21,6 & $15,9 \pm 9,9 a$ & Sözel ve Poster \\
\hline Ulusal Dermatoloji Kongresi [6] & $2006-2008$ & 2012 & 13,2 & $22,5 b$ & Sözel ve Poster \\
\hline Ulusal Radyoloji Kongresi [7] & $1995-2002$ & 2005 & 11,8 & 24,4 a & Sözel ve Poster \\
\hline Kuzey Amerika Plastik Cerrahi Derneği ${ }^{1}$ [15] & $2003-2007$ & 2012 & 57,7 & 19 a & Sözel \\
\hline Ingiliz Dermatologlar Topluluğu ${ }^{2}$ [16] & 2001 & 2004 & 51 & 18 a & Sözel ve Poster \\
\hline Amerikan Nöroradyoloji Derneği ${ }^{3}$ [17] & 1993 & 1997 & 37 & $15 \mathrm{a}$ & Sözel ve Poster \\
\hline Kuzey Amerika Menopoz Derneği ${ }^{4}$ [1] & $1999-2003$ & 2008 & 38,3 & $24 \pm 18 a$ & Sözel ve Poster \\
\hline
\end{tabular}

Yayına dönüştürülme süresi ortalama $\left({ }^{a}\right)$ ve ortanca olarak verilmiştir $\left({ }^{b}\right)$.

${ }^{1}$ American Society of Plastic Surgeons, ${ }^{2}$ British Association of Dermatologists, ${ }^{3}$ American Society of Neuroradiology, ${ }^{4}$ North American Menopause Society. olması ve yazarın geri çevrilmeler nedeniyle birden fazla dergiye çalışmasını göndererek uygun dergiyi bulma çabası bu süreyi daha da uzatmaktadır. Bu sorunun çözümü için yazarlara yeterli çalışma ortamı ile zamanın sağlanması ve dergilerin değerlendirme süreçlerinin hızlandırılması gerekmektedir. Bildiriler araştırma tipine göre incelendiğinde olgu sunumları en az yayına dönüștürülme oranına sahip olmuş fakat bu oran klinik araştırmalardan istatistiksel olarak anlamlı bir fark oluşturmamıştır. Yine de literatürde bir çok çalışmada benzer durum saptanmıştır [5-7, 15].Diğer taraftan çalışmamızda istatistiksel olarak anlamlı düzeyde en yüksek yayına dönüşme oranı deneysel çalışmalarda izlenmiştir. Bu durum deneysel araştımaların dergiler tarafından daha çok tercih edilmesinden ya da bu tarz araştırmaları yürüten yazarların deneysel araştırma yapabilmek için daha fazla bilgiye sahip olmaları gerekliliğinin doğurduğu bilgi birikiminden kaynaklanmış olmasıyla açıklanabilir.Üreme endokrinolojisi ve infertilite alanında üniversite hastanelerinden gönderilen bildiriler istatistiksel olarak anlamlı düzeyde diğer kurumlardan gönderilen bildirilerden daha fazla olmakla birlikte yayına dönüştürülme oranlarına bakıldığında eğitim 
ve araştırma hastaneleri ile aralarında anlamlı bir fark saptanmamıștır. Yine de oransal olarak üniversite hastanelerinde yapılan çalışmaların daha yüksek yayınlanma oranına sahip olduğu dikkatten kaçmamalıdır. Üniversitede çalışan araştırmacıların akademik çalışmalara daha çok önem vermesi ve gerekli zamanı daha kolay oluşturabilmeleri bu yüksek oranı açıklayabilir. Tıp Dergileri Editörleri Uluslararası Kurulu'nun kriterlerine göre yazar olarak adı geçen tüm bireylerin; çalışmanın tasarımında, verilerin analizinde ve yorumunda, makalenin yazımında veya bilimsel içeriğinin düzeltilmesinde, basıma hazır son şeklinin onaylanmasında görev alması gerekir [31]. Çalışmamızda değerlendirmeye alınan bildirilerin \%63'ünde yazar değişikliği yapıldığı saptanmıştır, bu oran literatürle oldukça benzerdir [1]. Araştırmaların bilimsel makale düzeyine ulaştırılması oldukça emek isteyen uzun bir süreçtir. $\mathrm{Bu}$ nedenle araştırmanın ilerleyen aşamalarında çalışmadan ayrılan araştırmacılar yayına dönüştürme sürecine yeterli katkıyı sağlayamamışlarsa makaleden isimleri çıkartılabilmekte, bununla birlikte yazım aşamasında görev alıp araştırma konusuna hakim olan ve çalışmanın tüm sorumluluğu taşıyan araştırmacıların isimleri de yazarlar arasına eklenebilmektedir. Çalıșmamızı kısıtlayan unsurlar arasında Türkçe yazım karakterleri nedeniyle uluslararası veri tabanlarında yayın taraması yaparken bazı yayınların saptanamamış olmasi yer almaktadir. Ayrica taramalarımızda literatürdeki benzer birçok çalışmada kullanılan ve en geniş veri tabanları olan Pubmed ve Google Scholar veri tabanlarını kullanmış olmamıza rağmen OvidSP, EBSCO, Thomson Reuters, Scopus ve benzeri diğer veri tabanlarını kullanmamış olmamız sadece bu kaynaklar yardımıyla bulunabilecek bazı uluslararası makalelerin değerlendirmeye alınamamasına sebep olmuş olabilir [5, 6, 28, 32].

\section{SONUÇ}

2008-2010 Ulusal Jinekoloji ve Obstetrik Kongre'lerinde üreme endokrinolojisi ve infertilite alanında sunulan bildirilerin yayınlanma oranı ülkemizdeki diğer branşlarda yapılan kongre bildilerine kıyasla yüksek orandadır. Yine de bu oranın arttırılıp yabancı bildirilerle aynı düzeye gelmesi ve Türkiye'de gerçekleștirilen çalışmaların daha geniş çevrelere duyurulması gerekmektedir. Bunun için araştırmacıları yayına teşvik edici yöntemlerin geliştirilmesi, bildirilerin yayına dönüştürülme oranlarının düzenli olarak analiz edilmesi, araştırmacılar için gerekli zamanın ve fiziki şartların sağlanması, yayına dönüştürülme oranlarında karşılaşılan düşüklüğün olası sebeplerinin irdelenmesi ve çözüme ulaştırılması gerektiğine inanmaktayız.

\section{KAYNAKLAR}

1. Schnatz PF, Romegialli A, Abrantes J, Marakovits $K$, Cunningham D, O'Sullivan DM. The North American Menopause Society: from abstract to publication. Menopause 2008;15(5):996-1001.

2. Schulte TL, Trost M, Osada N, Huck K, Lange T, Gosheger G, et al. Publication rate of abstracts presented at the Annual Congress of the German Society of Orthopaedics and Trauma Surgery. Arch Orthop Trauma Surg. 2012;132(2):271-80.

3. Autorino R, Quarto G, Di Lorenzo G, De Sio M, Damiano R. Are abstract presented at the EAU meeting followed by publication in peerreviewed journals? A critical analysis. Eur Urol. 2007;51(3):83340.

4. Scherer RW, Langenberg P, von Elm E. Full publication of results initially presented in abstracts. Cochrane Database Syst Rev. 2007;18:(2).

5. Kalyoncu U, Çınar M, Demiră̆ MD, Yılmaz S, Erdem H, Kiraz S, et al. Ulusal Romatoloji Kongrelerinde sunulan bildirilerin irdelenmesi: Neredeyiz? RAED Dergisi 2011;3(1-2):6-10.

6. Özyurt S, Kaptanoğlu AF. 2004- 2008 Yillart Arasinda Iki Yilda Bir Yapilan Ulusal Dermatoloji Kongrelerinde Sunulan Özetlerin Yayınlanma Oranlart. Dermatoz 2012;3(1):7-11.

7. Seçil M, Uçar G, Şentürk Ç, Karasu Ş, Dicle O. Publication rates of scientific presentations in Turkish national radiology congresses. Diagn Interv Radiol 2005; 11:69-73.

8. Kaya Mutlu E, Çelik D, Mutlu C, Razak Özdinçler A. Publication rates of oral presentations accepted at Advances in Physiotherapy Symposiums. Turk J Physiother Rehabil. 2013;24(2):145-9.

9. Riordan FA. Do presenters to pediatric meetings get their work published? Arch Dis Child 2000;83(6):524-6.

10. Roy D, Sankar V, Hughes JP, Jones A, Fenton JE. Publication rates of scientific papers presented in the Otorhinolarygological Research Society meetings. Clin Otolaryngol Allied Sci 2001;26(3):2536.

11. Macdonald A L, Parsons C, Davenport M. Outcome of abstracts presented at the British Association of Paediatric Surgeons congresses (1999-2008). $J$ Pediatr Surg 2012;47(2):386-90.

12. Evers JL. Publication bias in reproductive research. Hum Reprod 2000;15;2063-6.

13. Gilbert WM, Pitkin RM. Society for Maternal-Fetal Medicine meeting presentations: what gets published and why? Am J Obstet Gynecol. 2004;191(1):32-5. 
14. Davies MW, Dunster KR, East CE, Lingwood $B E$. Fate of abstracts published in the proceedings of the first annual Perinatal Society of Australia and New Zealand Congress in 1997. J Paediatr Child Health. 2002;38(5):501-6.

15. Gregory TN, Liu T, Machuk A, Arneja JS. What is the ultimate fate of presented abstracts? The conversion rates of presentations to publications over a five-year period from three North American plastic surgerymeetings. Can JPlast Surg. 2012;20(1):33-6.

16. Morgan CJ, Cooper AJ, Dyer JP, Friedmann PS. The publication rate of abstracts presented at the British Association of Dermatologists Annual Meeting. Br J Dermatol. 2005;153(4):855-7.

17. Marx WF, Cloft HJ, Do HM, Kallmes DF. The fate of neuroradiologic abstracts presented at national meetings in 1993: rate of subsequent publication in peer-reviewed, indexed journals. AJNR Am J Neuroradiol. 1999;20(6):1173-7.

18. Peng PH, Wasserman JM, Rosenfeld RM. Factors influencing publication of abstracts presented at the AAO-HNS Annual Meeting. Otolaryngol Head Neck Surg. 2006;135(2):197-203.

19. Lee DJ, Yuan JC, Prasad S, Barao VA, Shyamsunder N, Sukotjo C. Analysis of abstracts presented at the prosthodontic research section of IADR General Sessions 2004-2005:demographics, publication rates, and factors contributing to publication. J Prosthodont. 2012;21(3):225-31.

20. Chung KJ, Lee JH, Kim YH, Kim TG, Ha JH. How many presentations are published as full papers? Arch Plast Surg. 2012;39(3):238-43.

21. Patel AJ, Cherian J, Fox BD, Whitehead WE, Curry DJ, Luerssen TG, et al. Publication patterns of oral and poster presentations at the annual meetings of the Congress of Neurological Surgeons and the American Association of Neurological Surgeons. J Neurosurg. 2011;115(6):1258-61.

22. Rao AR, Beatty JD, Laniado M, Motiwala $H G$, Karim OM. Publication rate of abstracts presented at the British Association of Urological Surgeons Annual Meeting. BJU Int 2006;97(2):306-9.
23. Balasubramanian SP, Kumar ID, Wyld L, Reed $M W$. Publication of surgical abstracts in full text: a retrospective cohort study. Ann $R$ Coll Surg Engl. 2006;88(1):57-61.

24. Rodriguez JL, Laskin DM. Subsequent publication of oral and maxillofacial surgery meeting abstracts. J Oral Maxillofac Surg. 2012;70 (5):1261-4.

25. Winnik S1, Raptis DA, Walker JH, Hasun M, Speer T, Clavien PA. From abstract to impact in cardiovascular research: factors predicting publication and citation. Eur Heart J. 2012; 33 (24): 3034-45.

26. Ng L, Hersey K, Fleshner N. Publication rate of abstracts presented at the annual meeting of the American Urological Association. BJU Int 2004;94(1):79-81.

27. Yoo $S$, Oh $G$, Wang JC. Publication rates of presentations made at annual meetings of the American Orthopaedic Society for Sports Medicine and the Arthroscopy Association of North America. Am J Orthop (Belle Mead NJ) 2002;31(6):367-9.

28. Petticrew M, Gilbody S, Song F. Lost information? The fate of papers presented at the 40th society for Social Medicine Conference. J Epidemiol Community Health 1999;53(7):442-3.

29. Scherer RW, Dickersin K, Langenberg P. Full publication of results initially presented in abstracts. A meta-analysis. JAMA 1994;272(2):158-62.

30. Walby A, Kelly AM, Georgakas C. Abstract to publication ratio for papers presented at scientific meetings: how does emergency medicine compare? Emerg Med (Fremantle) 2001;13(4):460-4.

31. Declaration of Vancouver. Br Med J 1978;1 (6123):1302-3.

32. Yoon PD, Chalasani V, Woo HH. Conversion rates of abstracts presented at the Urological Society of Australia and New Zealand (USANZ) Annual Scientific Meeting into full-text journal articles. BJU Int 2012;110(4):485-9. 